\title{
Aspectos constitucionais do direito à imagem do atleta profissional de futebol
}

\section{CONSTITUCIONAL ASPECTS OF THE PROFESSIONAL FOOTBALL ATHLETE RIGHT TO IMAGE}

\author{
Francele Moreira Marisco *
}

Resumo: Pretende-se demonstrar a importância da proteção jurídica da imagem do atleta profissional de futebol, tanto no direito brasileiro como em âmbito internacional, frente aos avanços tecnológicos que acarretam situações de riscos à personalidade humana, bem como à investigação da possibilidade relativa de disponibilidade desse direito de personalidade. $\mathrm{O}$ problema é que a disponibilidade desse direito, através do contrato de licença de uso de imagem, volta-se geralmente apenas para o aspecto econômico da pessoa em si, não para a valorização da pessoa humana. Busca-se obter uma nova dimensão desse direito centrado no princípio da dignidade da pessoa humana como valor guia e princípio supremo da ordem jurídica.

Palavras-chave: Direito à Imagem. Atleta Profissional de Futebol. Dignidade da Pessoa Humana.

Abstract: It is intended to demonstrate the importance of lawfully protecting the professional soccer player image, both in Brazilian law as internationally, in the face of technological advances that lead to situations of risk to human personality, as well as research on the possibility of availability of the right personality. The problem is that the availability of this right through the license agreement to use image, usually back up only to the economic aspect of the person themselves, not for the value of the human person. Looking to get a new dimension that right centered on the principle of human dignity as a value guide and supreme principle of law.

* Especialista em Direito do Keywords: Right to Image. Professional Sport Football. Dignity of the Human Person. Consumidor pela Universidade de Coimbra/Portugal (2006); Mestre pela Universidade do Vale do Rio dos Sinos/UNISINOS (2009) e Professora do Centro Universitário Luterano de Ji-Paraná (RO) - ULBRA. E-mail: francelemarisco@hotmail.com 


\section{INTRODUÇÃO}

O presente trabalho tem o propósito de demonstrar a importância cada vez maior que o direito à imagem vem assumindo no nosso ordenamento jurídico brasileiro e internacional, considerando-se que deve ser reforçada sua proteção, pois se trata de um direito da personalidade.

No caso específico, tratar-se-á especialmente do direito à imagem do atleta profissional de futebol, pois como integra o imaginário popular é um excelente apelo à publicidade dos mais variados produtos.

Pretende-se, deste modo, obter uma nova dimensão desse direito centrada na pessoa humana, e não apenas no seu patrimônio, ou seja, não apenas no aspecto econômico que rege esta disponibilidade do direito à imagem do atleta profissional de futebol. Impõem-se, portanto, o princípio da dignidade da pessoa humana como guia para orientar as condutas consideradas essenciais no âmbito dos direitos da personalidade, servindo de alicerce para a ordem jurídica democrática.

\section{O CONSENTIMENTO DO DIREITO À PRÓPRIA IMAGEM}

O direito à imagem mantém todas as características e qualidades dentro do conjunto dos direitos da personalidade, gênero do qual é espécie. Contudo diferencia-se daqueles, uma vez que o direito à imagem é dotado de certa disponibilidade por parte do seu titular.

O direito a imagem pode ser objeto de posse, propriedade, cessão, transmissão, bem como suscetível de avaliação em dinheiro.

É essa característica que irá permitir sua entrada no comércio jurídico. $\mathrm{O}$ uso da imagem humana na publicidade, nos meios de comunicação, na divulgação de produtos e serviços, somente é possível em função dessa disponibilidade. É essa parcial disponibilidade que permite que o titular do direito colha frutos econômicos usando seus traços fisionômicos, seu corpo.

Isso começou a ocorrer com o crescimento do uso publicitário da imagem, quando se verificou que disso poder-se-ia obter lucro. A exploração econômica ganhou ares de comércio, no entanto, para que tal uso seja lícito é necessário que as pessoas (atletas, artistas, modelos, etc.) autorizem não apenas a reprodução da sua imagem (exemplo o retrato), mas também a respectiva veiculação. Deste modo, caracteriza o direito à imagem numa 
concepção negativa dos direitos de personalidade, a qual visa impedir que terceiros, sem autorização da pessoa, registrem sua imagem ou a reproduzam, qualquer que seja o meio. Assim, a imagem física das pessoas, no caso do presente trabalho, do atleta (retrato, filme, desenho), é juridicamente protegida contra a exposição ou reprodução por outrem.

Nesse sentido, disponibilidade significa "a liberdade jurídica de exercer certos direitos de personalidade de forma ativa ou positiva, não apenas na forma negativa, como tradicionalmente se pensou." (BORGES, 2007). Percebe-se que o exercício dos direitos de personalidade, em sua acepção positiva, está inserido na esfera de atuação privada da pessoa, não se identificando com o direito de privacidade enquanto espécie dos direitos de personalidade. Dessa forma, a incidência da autonomia privada sobre o direito à imagem implica o poder de disposição sobre tal direito.

Isso ocorre quando o titular do direito à imagem autoriza sua utilização. Tal permissão importa atos de relativa disposição do direito à imagem, logo, âmbito de incidência da autonomia privada sobre os direitos de personalidade. Assim, é lícita a realização de negócios jurídicos que tenham como objeto a utilização da imagem de alguém, mesmo nos negócios jurídicos onerosos.

Aqui cabe destacar, que essa disponibilidade do direito à imagem do atleta profissional de futebol volta-se para o aspecto mercadológico da pessoa em si. Na verdade, tanto os atletas, como as partes envolvidas neste contrato, visam prioritariamente o aspecto financeiro e os ganhos que esse contrato possa lhe trazer.

O importante é admitir a possibilidade de transmissão dos efeitos patrimoniais sem que isso leve à conclusão precipitada de descaracterização como direitos intransmissíveis e inalienáveis. O que não é possível é transmitir e alienar o direito em si, mesmo que gratuitamente, já que os direitos que decorrem da personalidade são inerentes a esta e, portanto, inseparáveis, da pessoa humana.

Essa relativa disponibilidade do direito à imagem, por muito tempo não era aceita pela maioria da doutrina, já que no direito interno, a regra do artigo 11 do Código Civil proíbe renuncia e limitações voluntárias, salvo as autorizadas em lei. Já em âmbito internacional somente previa esta disponibilidade quando fosse livre o seu consentimento, não sendo obrigado.

Ao caracterizar os direitos de personalidade, deve-se tomá-los como extrapatrimoniais e intransmissíveis, admitindo sua disponibilidade em certos 
casos. Nesse sentido, a disponibilidade dos direitos de personalidade é admitida até mesmo para permitir a melhor fruição por parte de seu titular, desde que o direito não seja descaracterizado. Em função dessa disponibilidade tem-se o respectivo ingresso no comércio jurídico.

Portanto, os direitos de personalidade, em especial, o direito à imagem, pode se admitir certa disponibilidade sobre estes direitos. Mas em se tratando de atletas famosos (como também os atores e modelos), o atentado assume proporções maiores, em vista do alto poder atrativo de sua imagem, em face da pronta identificação com o seu público.

Assim, há uma contradição na própria disponibilidade desse direito à imagem, na medida em que essa disponibilidade através do contrato de licença de uso da imagem não tem o objetivo de valorizar a pessoa humana, pois segue esta lógica mercadológica. Mas, por outro lado, a dignidade existe para preservar a autonomia e a liberdade da pessoa. No entanto, a pessoa pode violar sua dignidade através da liberdade, ou seja, desse livre arbítrio sobre esse direito de disponibilidade da imagem.

Na verdade, nessa lógica do mercado que vincula esta disponibilidade, não há bem uma liberdade, pois na grande maioria das vezes, principalmente os atletas que não são famosos, ou aceitam assinar o contrato imposto pelo clube, ou não trabalham. Dessa forma, a pessoa pode violar sua dignidade através dessa liberdade. Diante disso, esta disponibilidade não significa automaticamente promover a dignidade da pessoa humana.

Nesse sentido, os direitos da personalidade devem ser considerados como essencialmente indisponíveis, mas que em determinadas situações podem ser legítimos atos de disposição que impliquem renuncia ou limitação, como no caso do atleta ceder sua imagem.

Outro ponto importante a ser citado é a previsão de indenização no artigo $5^{\circ}$ inciso $\mathrm{V}$ da Constituição Federal, a qual afasta qualquer possibilidade de presunção de autorização para o uso da imagem. A regra é a violação, sendo que a permissão concedida, sua exceção. Isto é, todas as vezes que a imagem da pessoa for utilizada sem sua autorização, pressupõe uma lesão a um dos atributos centrais de sua personalidade.

Assim, a licença para utilizar a imagem, qualquer que seja o fim, é elemento essencial e necessário para afastar a lesão. É apenas a autorização expressa que faz cessar qualquer direito à indenização prevista no texto constitucional. 
Esse direito a indenização já está assentado na jurisprudência, fixandose a indenização em consonância com a notoriedade da pessoa e as conseqüências do uso ilícito, bem como baseado na verba publicitária. Mas em se tratando de atletas famosos (como também os atores e modelos), o atentado assume proporções maiores, em vista do alto poder atrativo de sua imagem, em face da pronta identificação com o seu público.

Um exemplo de pedido de indenização que pode ser citado e que não obteve a licença para utilizar sua imagem, causando grandes comentários pela mídia, é o caso do atleta Ronaldo Nazário de Lima, que depois de brigar nove anos na Justiça, a família e os empresários do jogador não conseguiram receber indenização por danos morais pela publicação da obra Carrasco de Goleiros - Um Fenômeno Chamado Ronaldinho. O livro traz informações sobre a vida e a trajetória profissional dele, tanto nos clubes brasileiros como nos clubes internacionais.

O pedido de indenização foi negado pelo juiz Paulo Cícero Augusto Pereira, da $5^{\text {a }}$ Vara Cível de Ribeirão Preto (SP), sustentando que o livro é apenas uma coletânea de entrevistas dadas pelo próprio jogador, não identificando qualquer situação vexatória ou de constrangimento, nem mesmo invasão de privacidade. A ação foi ajuizada em 1998 por Sônia Barata Nazário de Lima, Nélio Nazário de Lima, Alexandre da Silva Martins e Reinaldo Menezes da Rocha Pitta, respectivamente os pais e empresários do jogador. Os empresários contestavam o direito de imagem de Ronaldo e os pais alegavam invasão de privacidade. Segundo eles, os fatos relatados na obra não eram verdadeiros. Por esse motivo queriam receber $\mathrm{R} \$ 160$ mil de indenização por danos morais, o que representa o valor da primeira edição de dez mil exemplares do livro postos à venda. Foram réus no processo a editora Palavra Mágica, responsável pela edição do livro, seu diretor responsável na época, Galeno Amorim Júnior, e os autores do livro, Luiz Puntel, Luiz Carlos Ramos e o jornalista Brás Henrique. A ação, no entanto, prosseguiu somente contra a editora e contra um dos autores. Ao analisar o pedido, o juiz entendeu que os empresários do jogador não tinham legitimidade para propor a ação, já que os direitos de imagem do jogador pertencem à empresa Gortim Corporation, pessoa jurídica que teria legitimidade para contestar a obra. Em relação ao pedido dos pais, o juiz Augusto Pereira decidiu que não houve qualquer dano capaz de gerar 
indenização por dano moral. Ele concluiu que a obra tem caráter informativo, já que escrito por vários escritores e jornalistas que armazenaram e colheram informações durante muito tempo acerca da vida profissional, não acarreta, assim, qualquer prejuízo a quem quer que seja e ao direito de imagem. $\mathrm{Na}$ época tentaram impedir a venda dos livros, mas o pedido foi afastado pelo juiz da causa e o processo julgado extinto.

Neste caso não houve o consentimento livre do atleta como pressuposto para o ato de disposição sobre o direito à imagem. No entanto, não foi assim que o juiz entendeu ao analisar o pedido.

Também constitui ilícito, passível de indenização (artigo $5^{\circ}$ inciso $\mathrm{V}$ da Constituição Federal), a ultrapassagem dos limites contratuais, quando ocorre o uso da imagem para fins diversos daquele ajustado previamente. O ilícito prescinde a finalidade econômica, não sendo necessário que haja o lucro para haver a lesão, o ilícito. A simples utilização, mesmo que os fins sejam sem valor econômico, constitui ato ilícito. Como é elemento inerente e constitutivo da personalidade do indivíduo, é direito absoluto, e apenas ele pode determinar como, e se, sua imagem será utilizada.

Cabe citar que na Espanha o consentimento tem que ser expresso e a licença será revogável a qualquer momento. Porém, isso não advém de construção doutrinária ou jurisprudencial, mas sim dos artigos 2.2 e 2.3 da Ley Orgânica 1/1982, "que disciplina a Protección Civil Del Derecho al Honor, a la Intimidad Personal y Familiar y a la Própria Imagen”. Já os Códigos Civis Italianos e português exigem o consentimento, porém não necessariamente expressos para o uso da imagem.

O caráter personalista desse direito possibilita que essa licença de uso possa ser revogada a qualquer momento, independentemente de ter sido cumprido total ou parcialmente o contrato.

O importante é ressaltar que o consentimento é expressão de autonomia privada, e quando estiver relacionado com algum ato de disposição sobre bens ligados à personalidade, deve estar funcionalizado aos interesses existenciais..Não pode, assim, atingir o núcleo essencial da dignidade, a finalidade é exercício positivo do direito que reflete o direito a autodeterminação pessoal decorrente da própria dignidade. 


\section{O PRINCÍPIO DA DIGNIDADE DA PESSOA HUMANA COMO FUNDAMENTO PARA A UTILIZAÇÃO DA IMAGEM DO ATLETA PROFISSIONAL DE FUTEBOL}

A consagração do princípio da dignidade da pessoa humana resulta de uma grande evolução histórica mundialmente, com a sua positivação especialmente após a segunda guerra mundial. Passou-se a reconhecer a necessidade de se respeitar o homem como pessoa humana, desde a Antiguidade até o Humanismo, com a Declaração Universal dos Direitos do homem e do Cidadão (1789), confirmada pela declaração Universal dos Direitos do Homem (1948), chegando às Constituições Contemporâneas.

No direito interno, o princípio da dignidade da pessoa humana tornouse um comando jurídico com o advento da Constituição Federal de 1988, classificado como um dos fundamentos da república Federativa do Brasil e avançou, significativamente, ao ser consagrado no artigo $1^{\circ}$ inciso III.

A Constituição Federal de 1988 espelha no seu texto garantias e direitos estabelecidos de modo paradigmático na Declaração Universal dos Direitos do Homem. Ela está fundamentada no Estado Democrático de Direito, caracterizando a ruptura com o regime autoritário militar instaurado em 1964, no qual ocorreu a supressão de direitos constitucionais.

Essa fase em que ocorreu a ditadura militar no Brasil, bem como as ditaduras latino-americanas, foi um obstáculo "na construção da democracia e no resgate da dignidade humana." Considerada uma época marcada pelo sofrimento e pela barbárie, tornou-se fundamental para o reconhecimento da dignidade humana. Mas com a Constituição Federal de 1988 foi reforçada a proteção dos direitos e das liberdades constitucionais. É nesse sentido, que não se pode esquecer que o fundamento do princípio da dignidade da pessoa humana passou por fatos marcantes, ocorridos durante o regime militar, inseridos na história.

Mas, sem dúvida, com a Constituição Federal de 1988 foi dado um grande destaque aos Direitos Fundamentais devido a sua grande importância ao longo dos tempos, pois é fruto do pós-guerra que acabou atingindo e influenciando toda a sociedade na construção desses direitos. Isso resultou na ampliação e concretização considerável dos direitos e garantias fundamentais, como os direitos individuais, coletivos, difusos, políticos e sociais, sendo o grande destaque conferido na história de conquistas dos direitos fundamentais da pessoa humana. 
Mas com a passagem do Estado Liberal para o Estado Social e, posteriormente, a consagração dos direitos e garantias fundamentais estampados na Constituição de 1988, notadamente os de cidadania e os individuais, simbolizou a superação de um projeto autoritário, pretensioso e intolerante que se impusera ao país por vários anos de ditadura.

Logo, vê-se que o Estado brasileiro foi inspirado em bases democráticas, influenciadas tanto pelo direito interno como internacional, as quais concebem o Estado voltado unicamente para o bem estar da pessoa humana e não o contrário, constituindo o ser humano a finalidade precípua do Estado, não mais a atividade estatal.

Este princípio confere sentido e valor à pessoa, significando que o homem é o centro e o fundamento de toda atividade. Desse modo, os direitos da personalidade têm sua base no princípio da dignidade da pessoa humana.

É nesse sentido, que Pietro Perlingieri afirma a existência de um direito geral da personalidade que protege a pessoa humana como um valor unitário. E esse direito geral da personalidade é, portanto, a dignidade da pessoa humana, a qual está presente em todos os seres humanos.

Deve-se reconhecer o ser humano como sujeito de direitos e, assim, o caráter único e insubstituível de cada ser humano, portador de um valor próprio, veio demonstrar que a dignidade da pessoa existe singularmente em todo indivíduo.

Segundo Ingo Wolfgang Sarlet a dignidade da pessoa é "a qualidade intrínseca e distintiva reconhecida em cada ser humano que o faz merecedor do mesmo respeito e consideração por parte do Estado e da comunidade".

Em relação à própria conceituação da pessoa humana, cabe ser citado o pensamento de Kant, pois o que caracteriza o ser humano e o faz dotado de dignidade especial é que ele nunca pode ser meio para os outros, mas fim em si mesmo. Como diz Kant, "o homem, e, duma maneira geral, todo o ser racional, existe como fim em si mesmo, não só como meio para o uso arbitrário desta ou daquela vontade."

Como o homem é um fim em si mesmo e, por isso, tem valor absoluto, não podendo, por conseguinte, ser usado como instrumento para algo, não tem preço, e, justamente por isso tem dignidade, é pessoa.

Ao longo da evolução histórica passou-se a reconhecer a necessidade de se respeitar o homem como pessoa humana, mas no Brasil foi com a Constituição Federal de 1988, considerada "Constituição cidadã", que 
representou o grande marco na redemocratização do país, com uma relevante dimensão simbólica: ela marcou o reencontro da sociedade brasileira com o Direito e a Democracia.

Todavia, é preciso buscar a adequação do homem frente às próprias condições de possibilidade do ser humano. Deste modo, não se pode desconhecer e nem desconsiderar o papel efetivo do direito e da sociedade no que se refere à proteção e à promoção da dignidade da pessoa humana.

Diante destes aspectos, os direitos da personalidade, especialmente o direito à imagem, não pode ser mero objeto de interesse de outros indivíduos, pois o ser humano é sujeito de sua história e, por isso, que se deve haver o reconhecimento da dignidade da pessoa humana durante a evolução da vida. Além do mais, "o conteúdo da dignidade não é determinado expressamente pelo direito e dependerá das circunstâncias sociais e do próprio sentimento de dignidade que cada pessoa tem a respeito de si mesma." (BORGES, 2007)

\section{CONCLUSÃO}

Podemos afirmar que o direito à imagem do atleta profissional de futebol, tanto no direito brasileiro como no direito internacional, admite sua disponibilidade relativa, exatamente para permitir a melhor fruição por parte do seu titular, sem, no entanto, afetarem-se os seus caracteres intrínsecos. É essa relativa disponibilidade que permitirá que o titular do direito de imagem tire proveito econômico de sua imagem usando o seu alto poder atrativo.

Como esse direito à imagem faz parte de um conjunto maior conhecido como direitos da personalidade, procurou-se obter uma nova dimensão desse direito da personalidade, centrado na pessoa humana e não no patrimônio, que compreenderá as soluções para as lesões ao direito à imagem. Assim, o titular tem o direito de dispor do seu direito de imagem desde que respeite certos limites, bem como que o seu direito de autodeterminação tenha sempre o princípio da dignidade da pessoa humana como valor fundante, a qual serve de alicerce para à ordem jurídica democrática.

Portanto, considerar a existência de uma esfera de disponibilidade sobre os direitos da personalidade é tarefa que se impõe a todos os que pensam o Direito, ainda mais quando se almeja uma nova perspectiva do direito à imagem para o atleta profissional de futebol, baseada no princípio da dignidade da pessoa humana. 


\section{REFERÊNCIAS}

AMBIEL, Carlos Eduardo; SANTOS JÚNIOR, Walter Godoy. Relação entre contrato de trabalho e contrato de licença de uso de imagen. Revista do instituto Brasileiro de Direito Desportivo, n. 1, p. 52, 2002.

ANDRADE, Paes; BONAVIDES, Paulo. História Constitucional do Brasil. 8. ed. São Paulo: Editora, 2005.

BITTAR, Carlos Alberto. Os direitos da personalidade. 7. ed. Atual. por Eduardo Carlos Bianca Bittar. Rio de Janeiro: Forense Universitária, 2008.

BORGES, Roxana Cardoso Brasileiro. Direitos de personalidade e autonomia privada. 2. ed. rev. São Paulo: Saraiva, 2007. (Coleção do Prof. Agostinho Alvim / coordenação Renan Lotoufo).

CANOTILHO, Gomes e MOREIRA, Vital. Constituição da República Portuguesa Anotada, 2000.

CAPELO DE SOUZA, Rabindranath Valentino Aleixo. O direito geral de personalidade. Coimbra: Coimbra, 1995.

CHAVES, Antônio. Direitos conexos: atualizados de acordo com a nova Lei de Direitos Autorais, n. ${ }^{\circ}$ 9610, de fevereiro de 1988. São Paulo: LTR, 1999.

COMPARATO, Fábio Konder. A afirmação Histórica dos Direitos

Humanos. 4. ed. Saraiva: São Paulo, 2005.

EZBELLA, Felipe Legrazie. O direito desportivo e a imagem do atleta. São Paulo: IOB Thomson, 2006. 
HAUTTENHAUER, Hans. Conceptos fundamentales del Derecho Civil - introducción histórico-dogmática. Barcelona: Ariel, 1987.

KANT, Immanuel. Fundamentação da metafísica dos costumes e outros escritos. Tradução Leopoldo Holzbach. São Paulo: Editora Marin:Claret, 2005.

LA PRADA, Vicente Herce de. El derecho a la propria imagen y su incidencia en los medios de difusión. Barcelona: José Maria Bosh Editor, S.A, 1994.

MELO FILHO, Álvaro. Direito desportivo: novos rumos. Belo Horizonte: Del Rey, 2004.

MORAES, Walter. Direito à Própria Imagem (II), São Paulo: RT, v. 444, 1972.

MOREIRA, Vital. O Futuro da Constituição. In: GRAU, Eros; GUERRA FILHO, Willis Santiago (org). Direito Constitucional Estudo em Homenagem a Paulo Bonavides. São Paulo: Malheiros, 2001.

PERLINGIERI, Pietro. Perfis do Direito Civil. Traduzido por Maria Cristina De Cicco. 2. ed. Rio de Janeiro: Renovar, 2002.

ROUBIER, Unger; et al. Temas de Direito Civil. 3. ed. atual. Rio de Janeiro: Renovar, 2004.

SAAVEDRA, Luciano Cordero. EI Desportista Profesional (Aspectos Laborales e Fiscales). Valladolid: Lex Nova, 2001.

SARLET, Ingo Wolfgang. Dignidade da Pessoa Humana e Direitos Fundamentais na Constituição Federal de 1988. Porto alegre: Livraria do Advogado, 2004. 
STRECK, Lênio Luiz. Hermenêutica Jurídica e(em) crise: uma exploração hermenêutica da construção do direito. 7. ed. Porto Alegre: Livraria do Advogado, 2007.

ZAINAGHI, Domingos Sávio. Os atletas profissionais de futebol no direito do trabalho. São Paulo: Julex Livros, 1999.

Recebido em: 2012-11-09 Aprovado para publicação em: 2012-12-17

Como citar: MARISCO, Francele Moreira. Aspectos constitucionais do direito à imagem do atleta profissional de futebol. Scientia Iuris, Londrina, v.16, n.2, p.57-68, dez. 2012. DOI: $10.5433 / 2178-8189.2012 v 16 n 2 p 57$. 